\title{
Electrocardiographic changes in Chronic Obstructive Pulmonary Disease patients with elevated Pulmonary Artery Systolic Pressure
}

Humagain S, Keshari S, Gurung R, Pant P, Pokharel B, Koju R, Bedi TRS

\author{
Address for Correspondence: \\ Dr Sanjaya Humagain \\ Department of Medicine \\ Dhulikhel Hospital, Kathmandu University Hospital \\ sanjayahumagain@hotmail.com
}

\section{Abstract \\ Background}

Chronic Obstructive Pulmonary Disease (COPD) is a common global problem and most common medical problem in Nepal having significant morbidity and mortality. One of the pathogenesis of COPD in long run is the elevation of Pulmonary Artery Systolic Pressure (PASP) leading to right heart failure. A simple investigation - an Electrocardiograph (ECG) is assessed to co-relate with elevated PASP measured by Echocardiography in COPD patients of Dhulikhel Hospital.

\section{Methods and Materials}

A retrospective case control study of 342 COPD patients was done with assessment of ECG to co-relate with elevated PASP and with normal PASP. Data were analyzed using SPSS 17.

\section{Result}

There was significant difference in mean age, $\mathrm{P}$ amplitude in Lead II, III and aVF, QRS axis and R wave in $\mathrm{V}_{1}$ and $\mathrm{S}$ in $\mathrm{V}_{6}$ between two groups.

\section{Conclusion}

ECG changes are fairly sensitive and specific for elevation of PASP.

Key Words

COPD, PASP, Electrocardiograph, Echocardiography 


\section{Introduction}

Chronic Obstructive Pulmonary Disease (COPD) is a common global problem. It has been estimated that COPD will rise from sixth rank as the cause of death in $1990^{1}$ to third most common cause of death world wide by $2020^{1,2,3}$. According to a hospital based study, COPD is the most common medical problem in Nepal and has significant morbidity and mortality ${ }^{4}$. One of the pathogenesis of COPD in long run is the elevation of Pulmonary Artery Systolic Pressure (PASP) leading to right heart failure, reason for high morbidity and mortality 5 . PASP can be estimated correctly using echocardiography but unfortunately this is available only in few of tertiary hospitals ${ }^{6}$. It is expensive and requires highly specialized manpower. So in this study we try to look at a very simple investigation an Electrocardiograph (ECG) and co-relate this with the elevated PASP. ECG is simple, cheap, and available in most of the places and can be read even by the general physician.

\section{Methods and Materials}

Patients who were admitted in medical ward of Dhulikhel hospital, Kathmandu university hospital with the diagnosis of COPD from January $1^{\text {st }} 2010$ till December $31^{\text {st }} 2010$ and who were indicated for echocardiographic study by the clinicians were selected retrospectively. Patients with PASP more than $30 \mathrm{~mm} \mathrm{Hg}$ were taken as cases and those with less than $30 \mathrm{~mm} \mathrm{Hg}$ were taken as control.

160 patients with PASP $>30 \mathrm{mmHg}$ were identified and ECG was collected from each patient file. Similarly there were 182 patients with PASP $<30 \mathrm{~mm} \mathrm{Hg}$.

PASP was calculated according to TR Gradient ${ }^{6}$

\section{$4 T R^{2}+10 \mathrm{~mm} \mathrm{Hg}$}

Echocardiogram is performed by either one of the two cardiologists present at Dhulikhel Hospital using TOSHIBA power vision 6000 echocardiography machine.

ECG was taken using the standard method and calibration of $25 \mathrm{~mm} / \mathrm{s}$ and $10 \mathrm{~mm} / \mathrm{mv}$ by the ECG technician. ECG in both the groups were analyzed by the cardiologist.

Statistical Analysis was done using SPSS 17.0. Student's ttest was done to compare between the two groups.

\section{Results}

In patients with PASP $>30 \mathrm{mmHg}$, mean age is $58.5 \pm 6.2$ and in patients with PASP $<30 \mathrm{mmHg}$, mean age is $54.5 \pm 5.5$ $(p=0.01)$. Number of female patients were more than male patients in both the group.

There was significant increase in $P$ wave amplitude of
Lead II, III and aVF in elevated PASP group. Mean QRS axis was also increased significantly in PASP $>30 \mathrm{mmHg}$ group $(P=0.001)$. Similarly $R$ and $S$ amplitude are also increased in elevated PASP group.

Table 1 Difference in characteristic feature

\begin{tabular}{|c|c|c|c|}
\hline & $\begin{array}{c}\text { PASP }>30 \\
\mathrm{mmHg}\end{array}$ & PASP $<30 \mathrm{mmHg}$ & $P$ value \\
\hline $\begin{array}{l}\text { Age } \\
\text { Mean (years) } \\
\text { Range (years) }\end{array}$ & $\begin{array}{c}58.5 \pm 6.2 \\
42-86\end{array}$ & $\begin{array}{c}54.5 \pm 5.5 \\
40-76\end{array}$ & $\begin{array}{l}0.01 \\
0.03\end{array}$ \\
\hline $\begin{array}{ll}\text { Sex } & \\
& \text { Male (\%) } \\
& \text { Female (\%) }\end{array}$ & $\begin{array}{l}71(44.4) \\
89(55.6)\end{array}$ & $\begin{array}{l}86(47.3) \\
96(52.7)\end{array}$ & $\begin{array}{l}0.5 \\
0.5\end{array}$ \\
\hline $\begin{array}{l}\text { Mean P wave amplitude } \\
\text { Lead II }(\mathrm{mm}) \\
\text { Lead III }(\mathrm{mm}) \\
\text { Lead aVF }(\mathrm{mm})\end{array}$ & $\begin{array}{l}3.1 \pm 0.8 \\
2.4 \pm 0.7 \\
2.6 \pm 0.6\end{array}$ & $\begin{array}{l}2.3 \pm 0.6 \\
1.9 \pm 0.4 \\
2.1 \pm 0.5\end{array}$ & $\begin{array}{l}0.01 \\
0.03 \\
0.03\end{array}$ \\
\hline $\begin{array}{l}\text { Frontal plane QRS axis } \\
\text { (degree) }\end{array}$ & $129 \pm 12.5$ & $73 \pm 8.5$ & 0.001 \\
\hline$R$ amplitude in $V_{1}(\mathrm{~mm})$ & $7.6 \pm 1.3$ & $1.2 \pm 0.3$ & 0.001 \\
\hline$S$ amplitude in $V_{6}(\mathrm{~mm})$ & $18.0 \pm 5.6$ & $3.9 \pm 0.9$ & 0.02 \\
\hline
\end{tabular}

Similarly $P$ wave amplitude of more than $2.5 \mathrm{~mm}$ in lead II was $78.6 \%$ sensitive and $78 \%$ specific for elevated PASP. Complete RBBB was more specific (93.4\%). Poor progression of $R$ wave was neither sensitive (33.6\%) nor specific (27.4\%) for elevation of PASP group.

Table 2 Sensitivity and specificity for different ECG characteristics

\begin{tabular}{|l|c|c|c|c|}
\hline ECG characteristics & $\begin{array}{c}\text { PASP >30 } \\
\mathbf{m m ~ H g}\end{array}$ & $\begin{array}{c}\text { PASP <30 } \\
\mathbf{m m ~ H g}\end{array}$ & $\begin{array}{c}\text { Sensitivity } \\
\%\end{array}$ & $\begin{array}{c}\text { Specificity } \\
\%\end{array}$ \\
\hline P in lead II >2.5 mm & 126 & 42 & 78.6 & 78.0 \\
\hline R In V > 7 mm & 116 & 32 & 72.5 & 82.4 \\
\hline R/S ratio > 1 in V & 112 & 35 & 70.0 & 80.8 \\
\hline Incomplete RBBB & 106 & 82 & 66.3 & 54.9 \\
\hline Complete RBBB & 52 & 12 & 67.5 & 93.4 \\
\hline $\begin{array}{l}\text { Poor progression of } \\
\text { R wave }\end{array}$ & 54 & 132 & 33.6 & 27.4 \\
\hline $\begin{array}{l}\text { T inversion in lead } \\
\text { II,III, aVF }\end{array}$ & 120 & 26 & 75.0 & 85.7 \\
\hline $\begin{array}{l}\text { QRS axis }>\text { 110 } \\
\text { degree }\end{array}$ & 127 & 38 & 79.3 & 78.0 \\
\hline
\end{tabular}

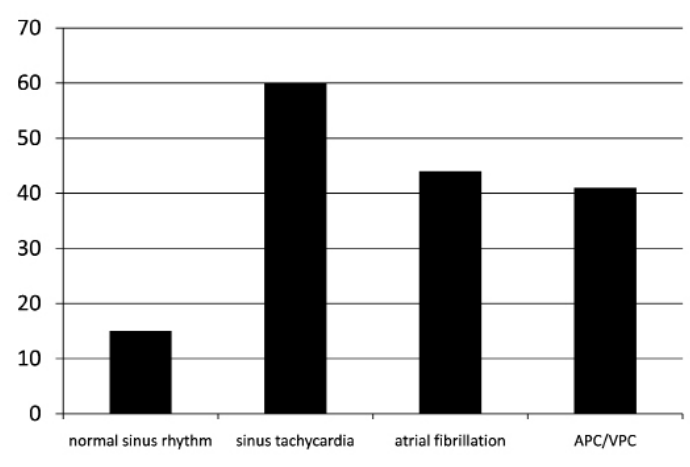

Fig 1 Rhythm in patients with PASP > $30 \mathrm{~mm} \mathrm{Hg}$ 


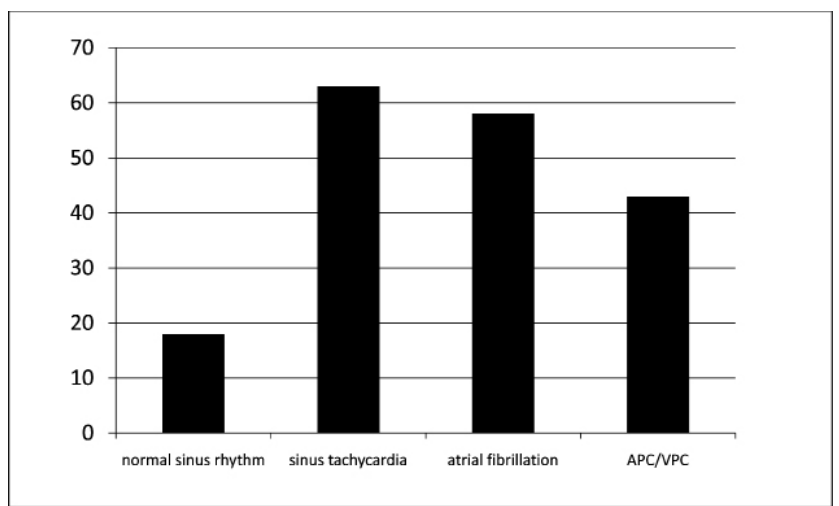

Fig 2 Rhythm in patients with $P A S P<30 \mathrm{~mm} \mathrm{Hg}$

\section{Discussion}

Pulmonary Artery Hypertension is a common complication of long standing COPD and is also a bad prognostic indicator ${ }^{5}$. ECG abnormalities corresponding with raised PASP is present in patients long before they have the symptoms of right heart failure ${ }^{7,8}$. Recent studies in rats and humans have illustrated that even a mildly increased right ventricular pressure load is associated with substantial changes in myocardial electrical properties, detectable in standard 12 lead ECG recording ${ }^{9,10}$.

In our study, we found that there was significant difference in P wave amplitude in lead II, III and aVF between the two groups. $\mathrm{P}$ wave amplitude in lead II $>2.5 \mathrm{~mm}$ was $78.6 \%$ sensitive and $78 \%$ specific for elevated PASP. However Ivor R. Henkens et.al. found it to be $30 \%$ sensitive and $91 \%$ specific ${ }^{10}$. P wave amplitude in lead II increases as result of progressive hypertrophy - associated diastolic dysfunction and RV dilatation leading to associated tricuspid regurgitation ${ }^{11}$. Karliner et al. documented increase in $P$ amplitude in lead II in healthy men who ascended from sea level to height of 6300 meters above sea level on Mount Everest and suffered from hypoxia induced $\mathrm{PAH}^{11}$. Our study being at hilly area is probably the reason for being more sensitive and less specific compared to that of Ivor R Henkens.

Height of $\mathrm{R}$ wave in $\mathrm{V}_{1}$ was $72.5 \%$ sensitive and $82.4 \%$ specific where as Henkens et al. found $53 \%$ sensitive and $94 \%$ specific $^{12}$. Similarly R/S ratio > 1 was $70 \%$ sensitive and $80.8 \%$ specific. In Henkens et al. it is $51 \%$ sensitive and $98 \%$ specific. We found complete RBBB to be $66.3 \%$ sensitive and $93.4 \%$ specific whereas Henkens et al. found it to be $18 \%$ sensitive and $96 \%$ specific. Increased height of R wave , $\mathrm{R} / \mathrm{S}$ ratio $>1$ in lead $\mathrm{V}_{1}$ and $\mathrm{RBBB}$ was found in yet another study by Henkens et $\mathrm{al}^{12}$. Poor progression of $\mathrm{R}$ wave was less sensitive and specific for elevated PASP, however T inversion in lead II, III and aVf was $75 \%$ sensitive and $85.7 \%$ specific.
QRS axis > 110 degree was $79.3 \%$ sensitive and $78.0 \%$ specific. Henkens et al found QRS axis >90 degree to be $84 \%$ sensitive and $96 \%$ specific. Similar ECG changes are reported in other studies also ${ }^{13,14,15}$.

When abnormalities are present in an ECG it is helpful to establish diagnosis but diagnosis cannot be ruled out in absence of ECG abnormalities. Numanik et al. also has the similar view ${ }^{16}$.

\section{Conclusion}

From this study we can conclude that recording 12 lead ECG is fairly sensitive and specific way to recognize elevated PASP in COPD patients. It can be used routinely in COPD patients as a screening purpose in cost effective manner. However whenever clinically required and echocardiogram is available, echocardiographic measurement of PASP is advised.

\section{References:}

1. Lopez AD, Murray CC. The global burden of disease, 19902020. Nature Med. 1998; 4:1241-3

2. Global initiative for Chronic Obstructive lung Disease. Global strategy for the diagnosis, management and prevention of chronic obstructive pulmonary disease. Executive summary. Medical communications Resources, Inc 2007; 1-43

3. Reilly JJ, Silverman EK, Shapiro SD, Chronic Obstructive Pulmonary Disease. Harrison's Principles of Internal Medicine (16 ${ }^{T H}$ ed.) New York; McGraw-Hill Medical Publishing Division 2005; 1547-54

4. Sayami A, Shrestha B. Critical care (Manual of ICU and CCU of teaching Hospital) $1^{\text {st }}$ ed. Kathmandu; JICA Medical Education Project 1995; 5-11

5. Mark A. Miller, Joesph M Sweeny, E. Clinton Lawrence and Kementh L. Brighm. Hurt's The Heart $13^{\text {th }}$ ed. 1655-1667

6. Otto textbook of clinical Echocardiography, $4^{\text {th }}$ ed.; $148-150$

7. Rich S, Dantzker DR, Ayres SM, Bergofsky EH, Brundage BH, Detre KM,et al. Primary pulmonary hypertension. A national prospective study Ann Intern Med 1987; 107: 216-23

8. Ahearn GS, Tapson VF, Rebeiz A, Greenfield JC Jr. Electrocardiography to define clinical status in primary pulmonary hypertension and pulmonary arterial hypertension secondary to collagen vascular disease. Chest 2002; 122: 5247

9. Henkens IR, Mouchaers KT, Vligen HW, van der Laarse WJ, Swenne CA, Maan AC, et al. Early changes in rat hearts with developing pulmonary arterial hypertension can be detected with three dimensional electrocardiography. Am J Physiol Heart Circ Physiol 2007; 293: H 1300-7 
10. Henkens IR, Mouchaers KT, Vonk- Noordegraaf A, Boonstra A, Swenne CA, Maan AC, et al. Improved ECG detection of presence and severity of right ventricular pressure load validated with cardiac magnetic resonance imaging. Am $j$ Physiol Heart Circ Physiol 2008; 294;H 2150-7

11. Karliner JS, Sarnquist FF, Graber DJ, Peters RM Jr., West JB. The electrocardiogram at extreme altitude: experience on Mt. Everest. Am Heart J 1985; 109:505-13

12. Ivo R. Henkens, C. Tji-Joong Gan, Sergee-A. van Wolferen, Miki Hew, Anco Boonstra, Jos W.R. Twisk, Otto Kamp et al. ECG monitoring of treatment response in Pulmonary Arterial hypertension Patients. Chest 2008; 134;1250-1257

13. Michael D. Puchalski, John S. Lozier, David J. Bradley, L. LuAnn Minch and Lloyd Y. Tani. Electrocardiography in the Diagnosis of Right Ventricular Hypertrophy in Children. Pediatrics 2006; $118 ; 1052$

14. Eduardo Bossone, Giuseppe Paciocco, Diana larussi, Angelo Agretto, Aldo lacono, Brenda W. Gillespie and Melvyn Rubenfire. The prognostic Role of the ECG in Primary Pulmonary Hypertension. Chest 2002; 121;513-518

15. R. L. Agarwal, Dinesh Kumar, Gurpreet, D.K. Agarwal,and G.S. Chabra. Diagnostic Values of echocardiogram in Chronic Obstructive Pulmonary Disease(COPD). Lung India 2008; AprJun;25(2);78-81

16. Al-Nuamanik K, Hijal T, Nguyen $\mathrm{V}$ et al. Predictive values of electrocardiogram in diagnosing Pul. HTN. Int. J cardiol 2008; 127:214-218 